악취 및 $\mathrm{VOC}$ 를 함유한 폐가스의 광촉매 처리: 2. 광도의 폐가스 처리효율에 대한 영향

\author{
이은주 $* * *$. 임광희 $* * *, \uparrow$ \\ *대구대학교 화학공학과 \\ 712-714 경상북도 경산시 진량읍 내리리 15 \\ **산업 및 환경폐가스연구소 \\ 712-714 경상북도 경산시 진량읍 내리리 15 \\ (2012년 10월 16일 접수, 2012년 11월 19일 채택)
}

\title{
Treatment of Waste Air Containing Malodor and VOC: 2. Effect of Light-intensity on the Photocatalytic Removal Efficiency of Malodor and VOC of Waste Air
}

\author{
Eun Ju Lee ${ }^{*, * *}$ and Kwang-Hee Lim ${ }^{*, * *, \dagger}$
}

*Department of Chemical Engineering, Daegu University, 15 Naeri-ri, Jillyang-eup, Kyungsan-si, Kyungbuk 712-714, Korea **Research Institute for Industrial and Environmental Waste Air Treatment, 15 Naeri-ri, Jillyang-eup, Kyungsan-si, Kyungbuk 712-714, Korea (Received 16 October 2012; accepted 19 November 2012)

\begin{abstract}
요 약
환형 광촉매반응기 외경지지체의 반사막에 의한 광촉매반응기시스템의 광도를 제고함으로써 개선된 광촉매반응기에 의한 악취성분 및 휘발성 유기화합물을 동시 포함한 폐가스의 처리를 수행하였다. 그리고 광도 제고가 각 운전조건에 서의 폐가스처리효율에 미치는 영향을 조사하였다. 광촉매 코팅된 nonporous glass bead 담체와 porous silica-based 담 체를 각각 광촉매반응기에 충전하였을 때에 반사필름이 부착된 개선된 광촉매반응기 외경에서 측정한 광도는, 반사필 름이 부착되지 않아서 광도가 제고되지 않은 광촉매반응기보다 각각 $30.1 \%$ 와 $28.5 \%$ 증가하였다. Porous silica-based 담체를 충전한 개선된 광촉매반응기의 제거효율에 대한 제고효과는 약 $2 \sim 3 \%$ 이었다. 그러나 glass-bead 담체를 충전했 을 때에 개선된 광촉매반응기의 제거효율 제고효과는 미미하였다. Porous silica-based 담체가 충전된 개선된 광촉매반 응기인 최적화 광촉매반응기의 경우의 황화수소 및 톨루엔 제거효율은 nonporous glass bead가 충전되고 반사막이 없 는 광촉매반응기 경우의 제거효율인 각각 $19 \%$ 와 $53 \%$ 보다 각각 약 $26 \%$ 와 약 $60 \%$ 의 증가율을 보였다. 반사막 필름표 면의 roughness가 종래의 상업용 거울의 roughness보다 4배 정도 컸으나, 향후 개선된 광촉매반응기의 반사막의 roughness를 개선할 경우에 광도 개선효과가 더욱 커져서 이에 따른 악취 및 VOC를 함유한 광촉매 처리효율이 더욱 제고되리라 예상된다.
\end{abstract}

\begin{abstract}
Abstact - The photocatalytic reactor was designed to have improved efficiency by enhancing a light intensity of photocatalytic reactor using a reflector coated on the surface at the outer radius of annular shaped photocatalytic reactor. The improved photocatalytic reactor performed to treat waste air containing malodor and VOC with the enhanced light intensity, of which the effect on their removal efficiency was investigated. The intensities of illumination of the improved photocatalytic reactor filled with porous silica-based media and nonporous glass bead media carrying photocatalyst were observed to increase by $28.5 \%$ and $30.1 \%$, respectively, compared to those of photocatalytic reactor without any reflector. Using the improved photocatalytic reactor filled with porous silica-based media and nonporous glass bead media carrying photocatalyst, the removal efficiencies were enhanced by $2 \sim 3 \%$ and insignificantly, respectively. The removal efficiencies of the optimized photocatalytic reactor with reflectors, filled with porous silica-based media carrying photocatalyst, were observed to increase by $26 \%$ and $60 \%$, compared to those of photocatalytic reactor (i.e., $19 \%$ and $53 \%$ ), without any reflector, filled with nonporous glass bead media carrying photocatalyst, for hydrogen sulfide and toluene, respectively. The roughness of used reflector surface was measured to be ca. four times as big as that of a commercial mirror. However, their removal efficiencies are expected to be enhanced by increasing an light intensity resulting from lowering the roughness of used reflector coated on the improved photocatalytic reactor in the future.
\end{abstract}

Key words: Photocatalytic Reactor, Light Intensity, Reflector, Removal Efficiency, Malodor, VOC

\footnotetext{
${ }^{\dagger}$ To whom correspondence should be addressed.

E-mail:khlim@daegu.ac.kr
} 


\section{1. 서 론}

$\mathrm{TiO}_{2}$ 같은 광촉매와 피산화물(오염원)의 더욱 효율적인 상호작용 때문에 활성탄, 알루미나, 실리카 및 제오라이트과 같은 흡착제를 $\mathrm{TiO}_{2}$ 와 혼합하거나 $\mathrm{TiO}_{2}$ 입자 표면에 실리카를 코팅할 때에, 이와 같 은 흡착제의 더욱 큰 비표면적 때문에 흡착이 더욱 효율적이고 따 라서 광촉매 분해율이 제고된다고 보고되었다[1-4] 한편 Nakano et al. [5]은 titanium tetraisopropoxide와 isopropanol의 혼합물을 silica beads에 함침, 가수분해 및 하소(calcination)를 하여 다공성의 $\mathrm{TiO}_{2}$ 담지 $-\mathrm{SiO}_{2}$ 담체를 제조하여 UV 조건 하에서 dinitrophenol을 광촉매 분해하였다. 최근에는 sol-gel 방법을 써서 $\mathrm{TiO}_{2} / \mathrm{SiO}_{2}$ aerogel [6] 또는 xerogel [7]을 제조하거나 $\mathrm{TiO}_{2}$ 를 담지한 실리카겔[8], $\mathrm{TiO}_{2}$ sol을 함 침한 실리카와 제오라이트 혼합물[9], tetraisoproxide를 실리카에 함 침한 소성물 [10] 등과 같이 광촉매를 담지한 광촉매담체를 광촉매 분해공정에 적용하였다. 이와 같이 광촉매 분해율을 높이기 위하여 광촉매담체 흡착능은 중요한 공정요소가 된다. 그럼에도 불구하고, 광촉매에 조사되는 광도 또한 광촉매공정에서 매우 중요한 요소이 다. 그 이유로서는 광도, 광촉매 담지량, 용존산소 농도(수처리의 경 우) 및 오염원 농도가 광촉매반응에 직접적으로 영향을 미치는 주 요변수이기 때문이다[11]. 이와 같이 광도는 광촉매 반응속도와 조 사에너지의 효율성에 직접적으로 영향을 주는 가장 중요한 인자 중 의 하나이다. 광촉매반응은 낮은 광도에서는 광도에 비례하고, 중간 광도에서는 광도의 제곱근에 비례하며, 높은 광도에서는 광도와 무 관하다고 보고되고 있다[12-14]. 또한 광도가 증가할수록 계면전하 이송에 대하여 상대적으로 전자-정공 재결합율이 커지며, 전자-정공 재결합 시에는 광자는 활용되지 못하고 열로서 방출된다. 따라서 전 자-정공 재결합에서 야기되는 에너지손실을 줄이기 위한 적합한 광 도를 결정하는 것이 중요하다[15]. 한편 이러한 특성을 가진 광촉매 공정과 바이오필터공정으로 구성된 하이브리드시스템으로 기상의 휘발성 유기화합물(VOC)을 시너지효과와 함께 처리하였음이 보고 되었다[16,17].

본 연구에서는 주어진 광원 하에서 광촉매반응기 외경지지체의 반사막에 의하여 광촉매에 조사되는 광도를 제고함으로써, 흡착능 이 없거나 있는 광촉매담체를 충전한 광촉매반응기의 효율을 높이 는 개선된 광촉매반응기를 운전하여 악취성분 및 휘발성유기화합물 로서 황화수소 및 톨루엔을 동시 포함한 폐가스의 처리를 수행하였 다. 그리고 그 결과를 본 논문 part1에서 수행한 광도의 제고없이 동일한 조건의 폐가스의 처리를 수행한 결과와 상호 비교하여, 광 도 제고가 각 운전조건에서의 폐가스처리효율에 미치는 영향을 조 사하였다. 또한 이 연구에서는 흡착능이 있는 광촉매담체를 충전하 고 동시에 광도를 제고한 최적조건에서 개선된 광촉매반응기의 폐 가스처리효율과, 흡착능이 없는 광촉매담체를 활용하고 광도를 제 고하지 않은 경우의 폐가스처리효율을 상호 비교하였다.

\section{2. 재료 및 방법}

\section{2-1. 실험장치 및 구성}

내부 광원으로부터 조사된 UV를 광촉매반응기 내부로 반사시킴 으로써 환형의 광촉매반응기 외경지지체를 통한 광투과 및 광흡수 손실을 최소로 하고 광도를 극대화하기 위하여, 논문 part1에서와 같은 실험장치 및 구성의 환형의 광촉매반응기 외경에 알루미늄이

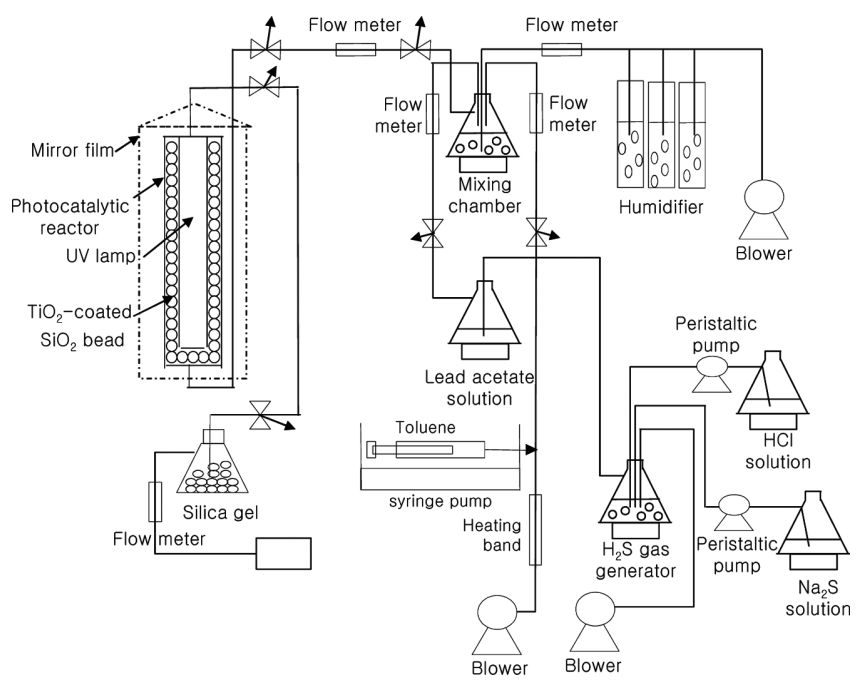

Fig. 1. Schematic diagram of improved photo-catalytic reactor fed with synthetic contaminated air containing hydrogen sulfide and toluene.

코팅된 반사 필름을 부착한 개선된 광촉매공정을 Fig. 1 과 같이 구 축하였다. 외경지지체를 통한 광투과 및 광흡수손실을 최소로 하는 반사막의 효과를 평가하기 위하여, 광촉매 코팅된 nonporous glass bead 또는 porous silica-based 담체로 충전된 알루미늄 코팅된 반사 필름으로 둘러싸여진 개선된 광촉매반응기들의 외경과 반사막 사이 의 각각의 광도를 조도계(Sechang Instruments, YK-34UV)로 측정 하였다.

\section{2-2. 개선된 광촉매반응기 운전조건}

악취 및 $\mathrm{VOC}$ 를 함유한 폐가스의 광촉매 처리효율에 대한 광도의 영향을 평가하기 위하여, nonporous glass bead와 porous silicabased 담체로 충전된 개선된 광촉매반응기들의 황화수소와 톨루엔 을 동시 함유한 폐가스의 처리효율을 Fig. 1과 같은 개선된 광촉매 반응기공정을 운전하여 각각 관찰하였다. Porous silica-based 담체 로 충전된 개선된 광촉매반응기의 경우는 흡착능과 광도가 동시 제 고되어 최적화된 광촉매반응기로서 악취와 $\mathrm{VOC}$ 를 함유한 폐가스 에 대한 광촉매 처리효율에 대한 영향평가를 수행하였다. 개선된 광 촉매반응기공정의 운전조건은 Table 1과 같으며 본 논문 part 1 과 같이 설정하였다.

\section{2-3. 광촉매반응기 제거효율 및 제거성능}

악취 및 $\mathrm{VOC}$ 를 함유한 폐가스의 광촉매 처리효율을 평가하기 위 하여, 광촉매반응기의 톨루엔 및 황화수소 제거효율(removal efficiency) 을 식 (1)에 준하여 계산하였다.

$$
\text { Removal efficiency }(\%)=\frac{\mathrm{C}_{i}-\mathrm{C}_{o}}{\mathrm{C}_{i}} \times 100
$$

Table 1. Operating conditions of improved photocatalytic reactor

\begin{tabular}{ccccc}
\hline \hline $\begin{array}{c}\text { Pollutants } \\
\text { in waste air }\end{array}$ & $\begin{array}{c}\text { Feed } \\
\text { concentration }\end{array}$ & $\begin{array}{c}\text { Blower } \\
\text { rate }\end{array}$ & $\begin{array}{c}\text { Air } \\
\text { flow rate }\end{array}$ & $\begin{array}{c}\text { Total } \\
\text { air rate }\end{array}$ \\
\hline $\begin{array}{c}\text { Toluene } \\
\mathrm{H}_{2} \mathrm{~S}\end{array}$ & $50 \mathrm{ppm}$ & $0.5 \mathrm{~L} / \mathrm{min}$ & $0.5 \mathrm{~L} / \mathrm{min}$ & $1.5 \mathrm{~L} / \mathrm{min}$ \\
\hline
\end{tabular}

Korean Chem. Eng. Res., Vol. 50, No. 6, December, 2012 
where $\mathrm{C}_{i}$ and $\mathrm{C}_{o}$ denote the concentrations of toluene or hydrogen sulfide of fed waste air and treated waste air, respectively.

한편 광촉매반응기의 톨루엔 및 황화수소의 제거성능(elimination capacity) 및 부하(inlet load)를 각각 식 (2)과 (3)에 준하여 계산하 였다.

Elimination capacity $\left(\mathrm{g} / \mathrm{m}^{3} / \mathrm{hr}\right)=\frac{\mathrm{C}_{i}-\mathrm{C}_{o}}{\tau}$

Inlet load $\left(\mathrm{g} / \mathrm{m}^{3} / \mathrm{hr}\right)=\frac{\mathrm{C}_{i}}{\tau}$

where 1) $\mathrm{C}_{i}$ and $\mathrm{C}_{o}$ denote the concentrations $\left(\mathrm{g} / \mathrm{m}^{3} / \mathrm{hr}\right)$ of toluene or hydrogen sulfide of fed waste air and treated waste air, respectively; 2) $\tau$ denotes empty bed contact time (hr) of improved photocatalytic reactor, obtained by dividing apparent volume of the media coated with photocatalyst by feed flow rate.

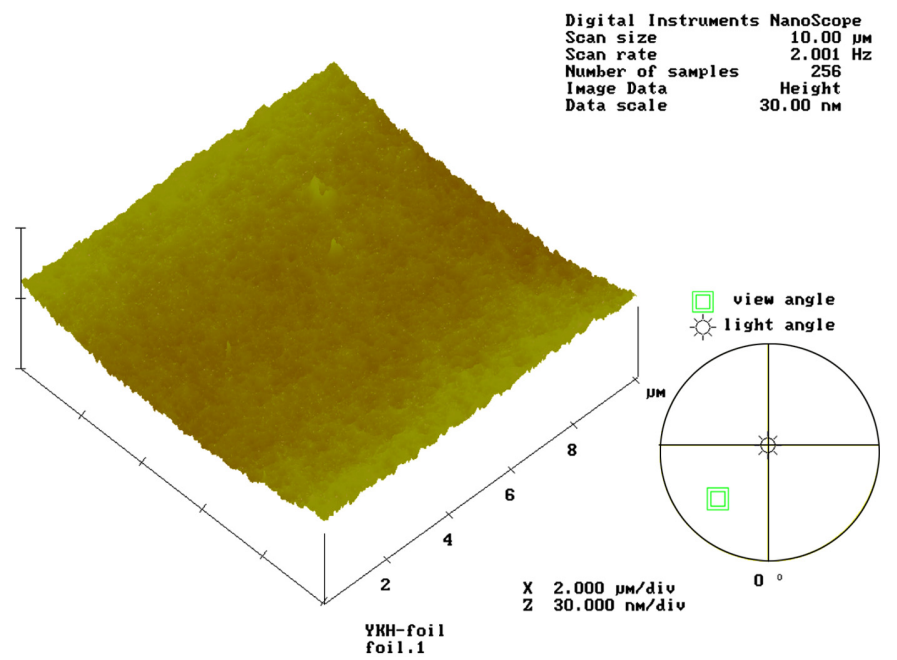

(a)

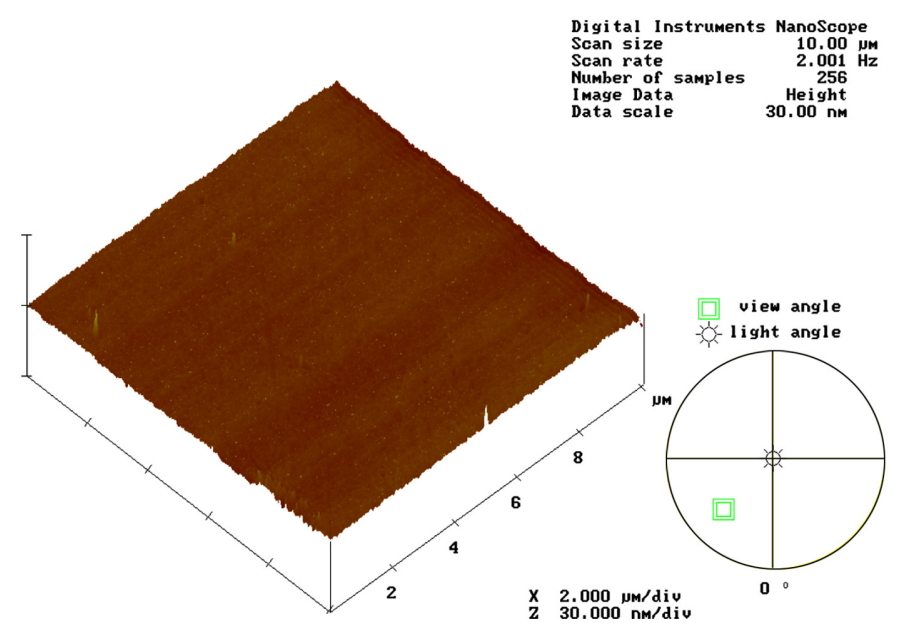

mirror.1

\section{2-4. 반시필름의 roughness 측정}

환형의 개선된 광촉매반응기 외경에 부착된 알루미늄이 코팅된 반사 필름의 표면과 종래의 질산은 도금을 한 상업용 거울의 표면을 scanning probe microscope(Digital Instrument, Nanoscope IIIa)로 표면의 roughness를 측정하였다.

\section{3. 결과 및 토론}

\section{3-1. 개선된 광촉매반응기의 광도 및 특성}

3-1-1. 반사필름의 roughness 측정결과

개선된 환형 광촉매반응기 외경에 부착되는 반사필름 표면과 종 래의 질산은 도금을 한 상업용 거울의 표면을 scanning probe microscope (Digital Instrument, Nanoscope IIIa)로 Fig. 2a 및 b와 같이 이미지화하고 각 표면의 roughness를 측정하였다. 그 결과 반 사필름 표면과 종래의 상업용 거울의 roughness는 각각 $2.3 \mathrm{~nm}$ 및

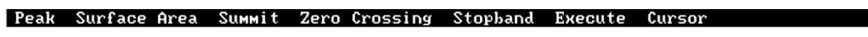

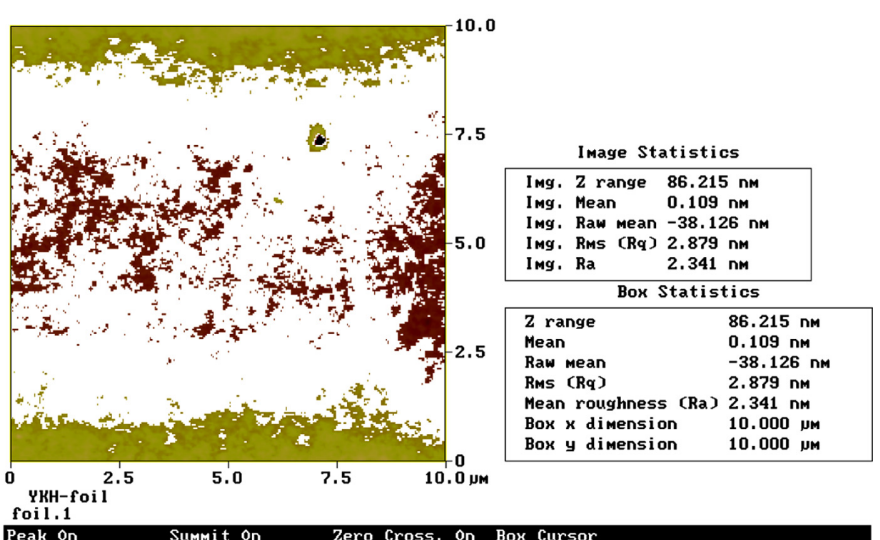

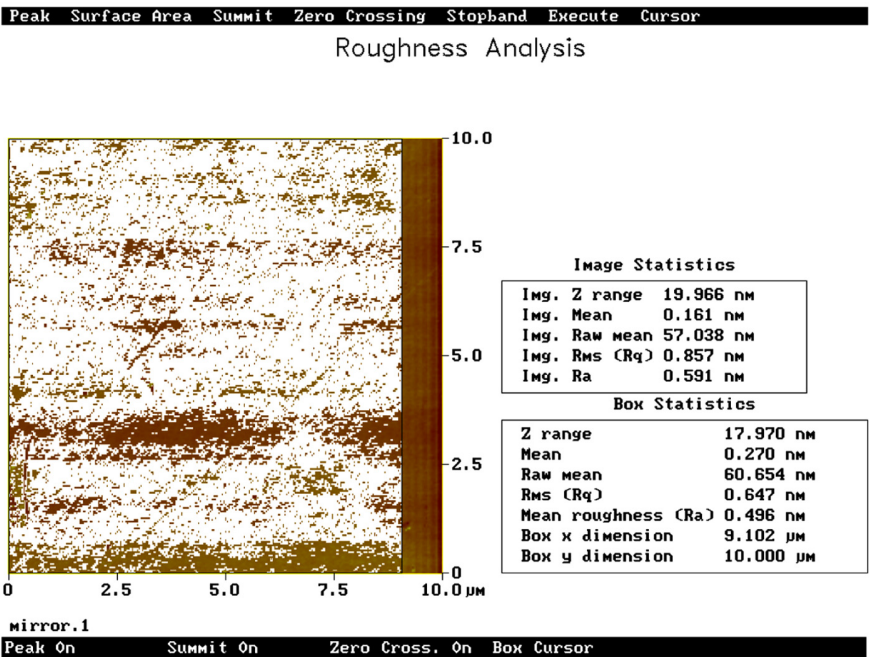

(b)

Fig. 2. (a) Image of scanning probe microscope for the surfaces of mirror foil Coated with aluminium; (b) Image of conventional mirror plated with silver nitrate.

Korean Chem. Eng. Res., Vol. 50, No. 6, December, 2012 
$0.5 \mathrm{~nm}$ 로서, 반사필름 표면의 roughness가 종래의 상업용 거울의 roughness보다 약 4배 정도 컸다.

3-1-2. 개선된 광촉매반응기와 반사막이 없는 광촉매반응기의 광 도 비교

광촉매 코팅된 nonporous glass bead 담체를 광촉매반응기에 충 전하였을 때에 반사막이 없는 UV/광촉매반응기 외경에서 측정한 광도는 $1.091 \mathrm{~mW} / \mathrm{cm}^{2}$ 이었고, 반사필름이 부착된 개선된 광촉매반 응기 외경에서 측정한 광도는 $1.419 \mathrm{~mW} / \mathrm{cm}^{2}$ 이었다. 한편 광촉매 코팅된 porous silica-based 담체를 광촉매반응기에 충전하였을 때에 반 사막이 없는 UV/광촉매반응기 외경에서 측정한 광도는 $1.12 \mathrm{~mW} /$ $\mathrm{cm}^{2}$ 이었고, 반사필름이 부착된 개선된 광촉매반응기 외경에서 측정 한 광도는 $1.439 \mathrm{~mW} / \mathrm{cm}^{2}$ 이었다. 따라서 반사필름이 부착된 개선 된 광촉매반응기 외경에서 측정한 광도는 광촉매 코팅된 nonporous glass bead 담체와 porous silica-based 담체를 각각 광촉매반응기에 충전하였을 때에, 반사필름이 부착되지 않아서 광도가 제고되지 않 은 광촉매반응기보다 광도가 각각 $30.1 \%$ 와 $28.5 \%$ 증가하였다.

\section{3-2. 개선된 광촉매반응기 운전 및 평가}

3-2-1. Porous silica-based 담체를 충전한 개선된 광촉매반응기 평가 Porous silica-based 담체로 충전된 개선된 광촉매반응기의 경우는 흡 착능과 광도가 동시 제고되어 최적화된 광촉매반응기이다. Porous silica-based 광촉매담체를 충전하고 반사필름을 부착한 개선된 광 촉매반응기를 Table 1과 같은 운전조건으로 72 시간 동안 운전하였 을 때에 폐가스 내에 동시 함유된 톨루엔 및 황화수소의 동시처리 농도 추이는 각각 Figs. 3,4와 같다. 또한 그에 따른 톨루엔 및 황화 수소의 동시처리효율에 대한 추이는 각각 Figs. 5,6과 같다. 동 실험 에서 시간에 따른 톨루엔 및 황화수소의 inlet load 및 elimination capacity의 추이는 각각 Figs. 7,8과 같다. 톨루엔 및 황화수소가 각 각 약 $50 \mathrm{ppm}$ 및 $25 \mathrm{ppm}$ 인 폐가스가 광촉매반응기에서 처리되어서 Figs. 3,4 와 같이 운전 초기에는 흡착에 의하여 $100 \%$ 까지 처리가 되 었으나 각각 약 6시간 이후부터 및 3시간 이전부터 breakthrough가 발생하여 각각 약 $7 \mathrm{ppm}$ 및 약 $18 \mathrm{ppm}$ 정도로 처리되었다. 따라서

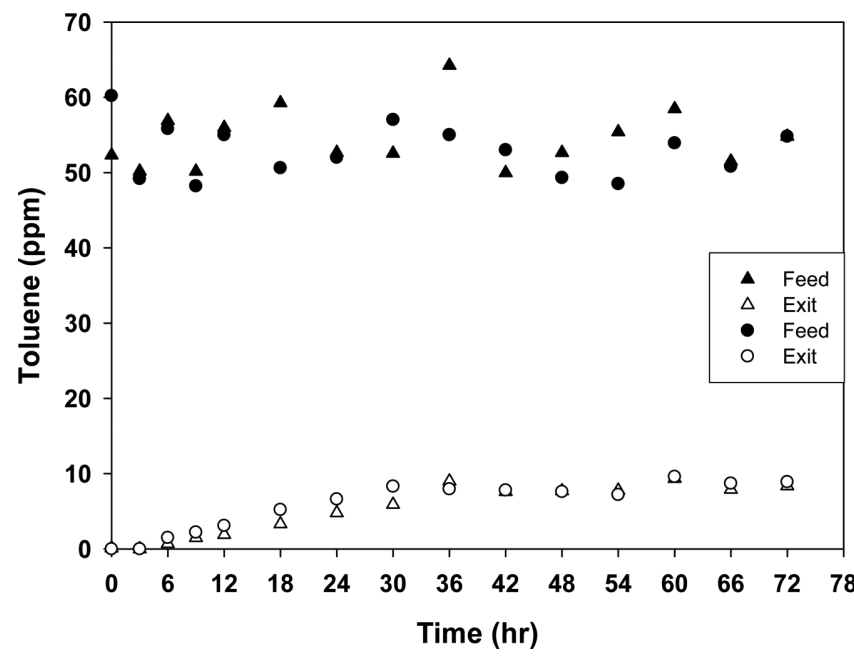

Fig. 3. Time-evolution of toluene concentration at the exit of UV/ photo-catalytic reactor packed with silica based porous media and covered with reflector (triangle) or without any reflector (round).

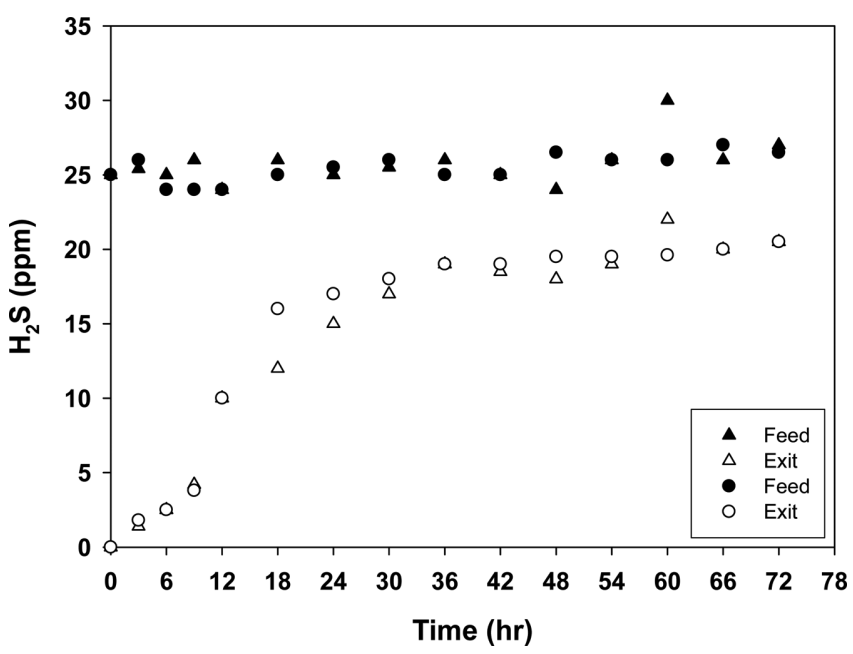

Fig. 4. Time-evolution of hydrogen sulfide concentration at the exit of UV/photo-catalytic reactor packed with silica based porous media and covered with reflector (triangle) or without any reflector (round).

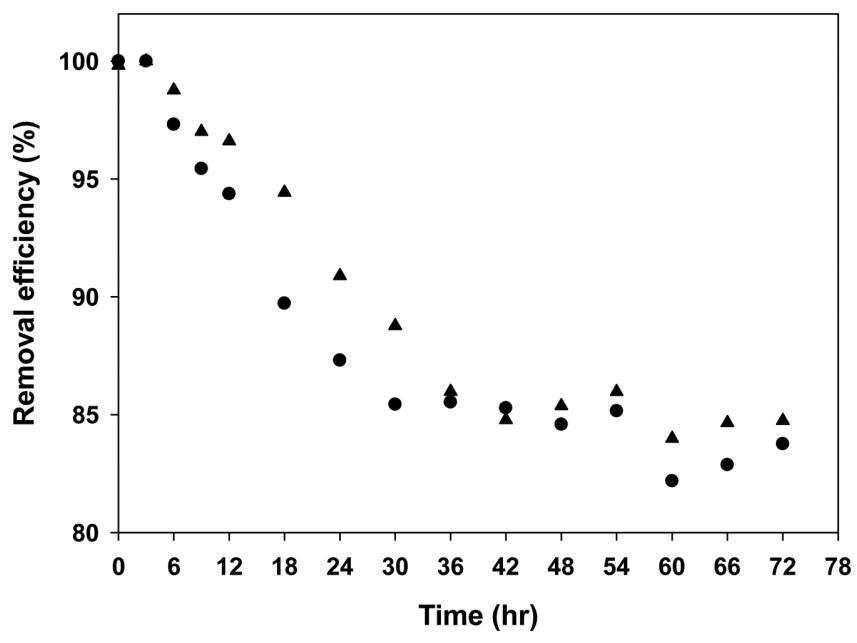

Fig. 5. Removal efficiency of toluene at the exit of UV/photo-catalytic reactor packed with silica based porous media and covered with reflector (triangle) or without any reflector (round).

톨루엔 및 황화수소의 제거효율은 Figs. 5,6에서와 같이 흡착에 의 한 $100 \%$ 완전제거에서부터 정상상태에서 각각 약 $85 \%$ 및 $24 \%$ 로 관찰되었다. 또한 톨루엔의 inlet load 및 정상상태의 elimination capacity는 Fig. 7과 같이 각각 약 $10 \mathrm{~g} / \mathrm{m}^{3} / \mathrm{hr}$ 및 $8 \mathrm{~g} / \mathrm{m}^{3} / \mathrm{hr}$ 이었고, 황 화수소는 Fig. 8 과 같이 각각 약 $1.8 \mathrm{~S}-\mathrm{g} / \mathrm{m}^{3} / \mathrm{hr}$ 및 $0.5 \mathrm{~S}-\mathrm{g} / \mathrm{m}^{3} / \mathrm{hr}$ 이 었다.

3-2-2. Nonporous glass bead 담체를 충전한 개선된 광촉매반응 기 평가

Nonporous glass bead를 충전하고 반사막을 증착한 UV/광촉매반 응기를 Table 1과 같은 운전조건으로 운전하였을 때에 폐가스 내에 동시 함유된 톨루엔 및 황화수소의 동시처리농도 추이는 각각 Figs. 9,10 과 같다. 또한 그에 따른 톨루엔 및 황화수소의 동시처리효율에 대한 추이는 각각 Figs. 11,12 와 같다. 동 실험에서 시간에 따른 톨 루엔 및 황화수소의 inlet load 및 elimination capacity의 추이는 각 


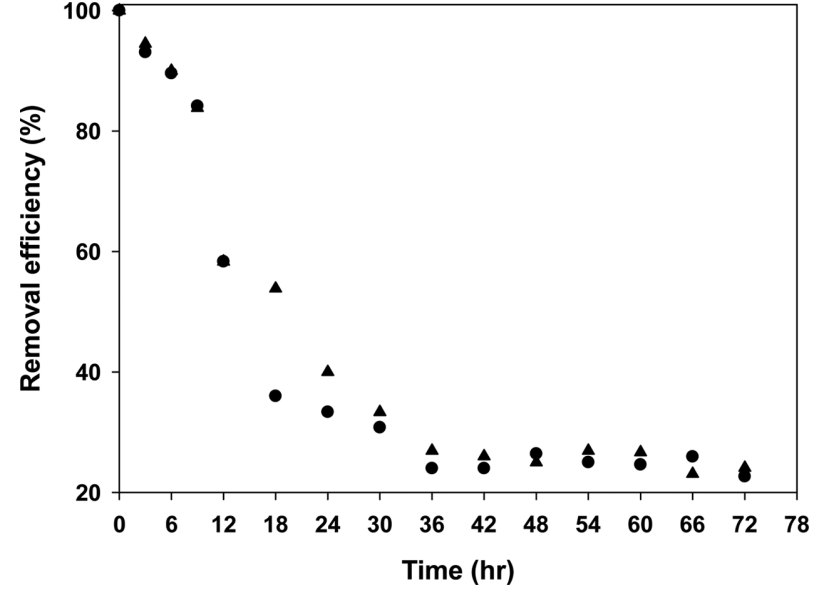

Fig. 6. Removal efficiency of hydrogen sulfide concentration at the exit of UV/photo-catalytic reactor packed with silica based porous media and covered with reflector (triangle) or without any reflector (round).

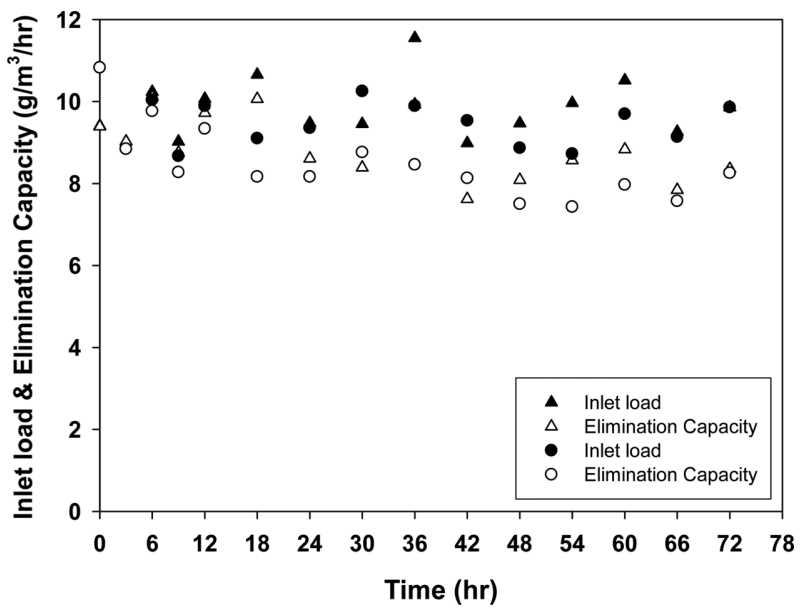

Fig. 7. Time-evolution of inlet load and elimination capacity of toluene of UV/photo-catalytic reactor packed with silica based porous media and covered with reflector (triangle) or without any reflector (round).

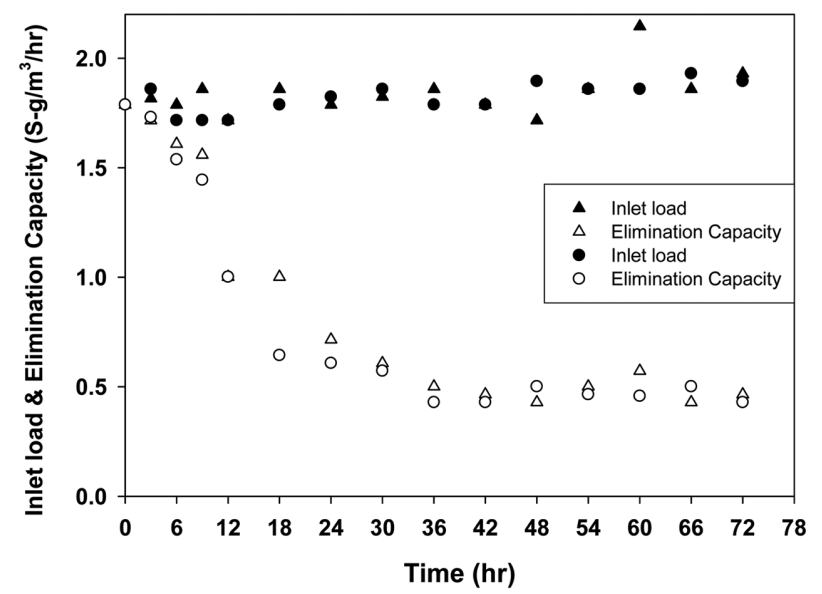

Fig. 8. Time-evolution of inlet load and elimination capacity of hydrogen sulfide of $\mathrm{UV} /$ photo-catalytic reactor packed with silica based porous media and covered with reflector (triangle) or without any reflector (round).

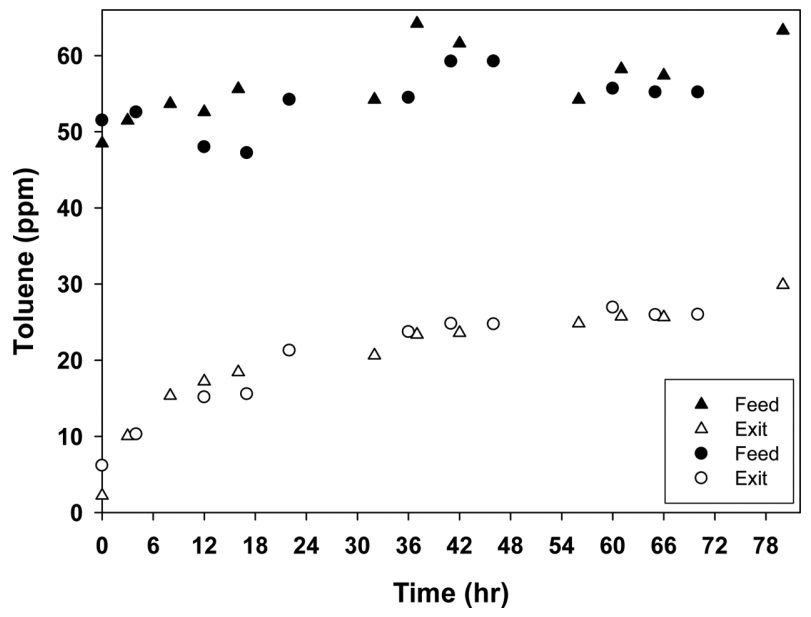

Fig. 9. Time-evolution of toluene concentration at the exit of UV/ photo-catalytic reactor packed with nonporous glass bead and covered with reflector (triangle) or without any reflector (round).

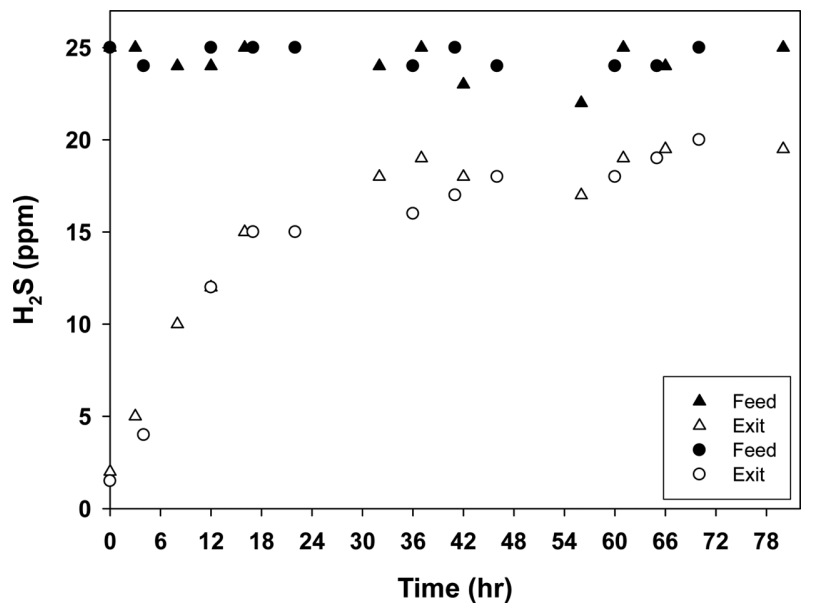

Fig. 10. Time-evolution of hydrogen sulfide concentration at the exit of $\mathrm{UV} /$ photo-catalytic reactor packed with nonporous glass bead and covered with reflector (triangle) or without any reflector (round).

각 Figs. 13,14 와 같다. 톨루엔 및 황화수소가 각각 약 $50 \mathrm{ppm}$ 및 $25 \mathrm{ppm}$ 인 폐가스가 광촉매반응기에서 처리되어서 Figs. 9,10과 같이 운전 초기에는 흡착에 의하여 거의 $100 \%$ 까지 처리가 되었으나 porous silica based 담체보다 훨씬 빠르게 포화되어 각각 약 $27 \mathrm{ppm}$ 및 약 $20 \mathrm{ppm}$ 정도로 처리되었다. 따라서 톨루엔 및 황화수소의 제 거효율은 Figs. 11,12 에서와 같이 흡착에 의한 $100 \%$ 완전제거에서 부터 정상상태에서 각각 약 $53 \%$ 및 $20 \%$ 로 관찰되었다. 또한 톨루 엔의 inlet load 및 정상상태의 elimination capacity는 Fig. 13과 같이 각각 약 $10 \mathrm{~g} / \mathrm{m}^{3} / \mathrm{hr}$ 및 $6 \mathrm{~g} / \mathrm{m}^{3} / \mathrm{hr}$ 이었고, 황화수소는 Fig. 14와 같이 각각 약 $1.8 \mathrm{~S}-\mathrm{g} / \mathrm{m}^{3} / \mathrm{hr}$ 및 $0.35 \mathrm{~S}-\mathrm{g} / \mathrm{m}^{3} / \mathrm{hr}$ 이었다.

\section{3-2-3. 광촉매 처리효율에 대한 광도의 영향평가}

Porous silica-based 담체가 충전되고 반사필름이 부착된 최적화 개선된 광촉매반응기의 경우에 톨루엔 및 황화수소 제거효율은 각 각 $85 \%$ 및 $24 \%$ 로서, 반사필름이 부착되지 않은 광촉매반응기 경

Korean Chem. Eng. Res., Vol. 50, No. 6, December, 2012 


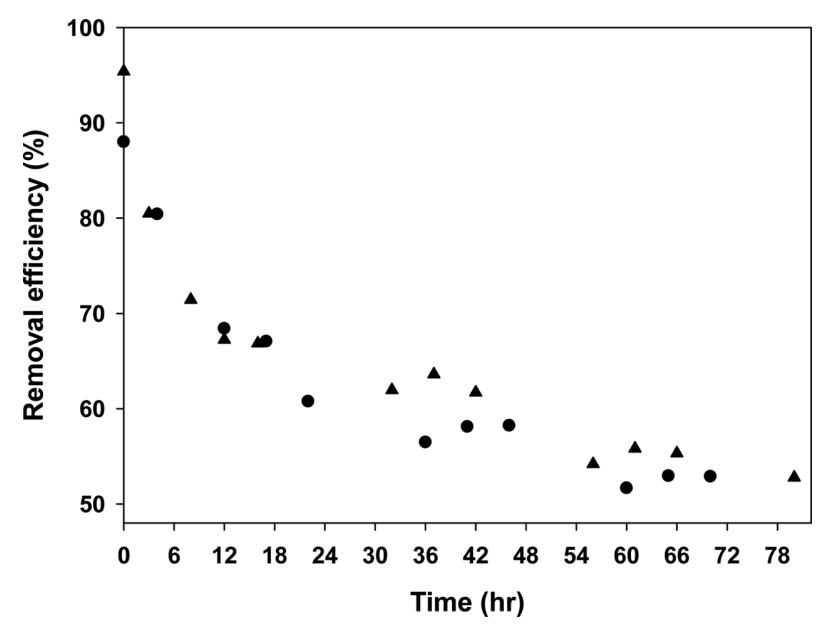

Fig. 11. Removal efficiency of toluene at the exit of UV/photo-catalytic reactor packed with nonporous glass bead and covered with reflector (triangle) or without any reflector (round).

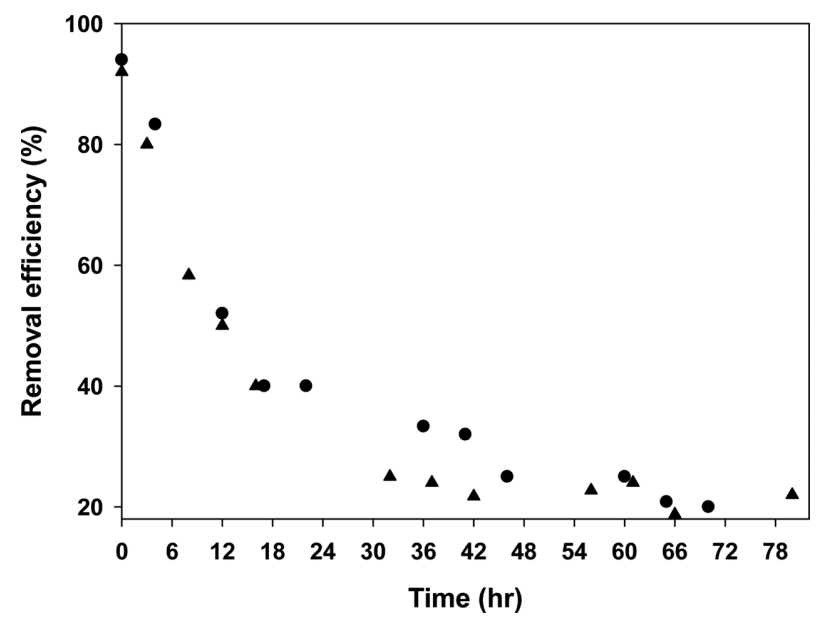

Fig. 12. Removal efficiency of hydrogen sulfide concentration at the exit of UV/photo-catalytic reactor packed with nonporous glass bead and covered with reflector (triangle) or without any reflector (round).

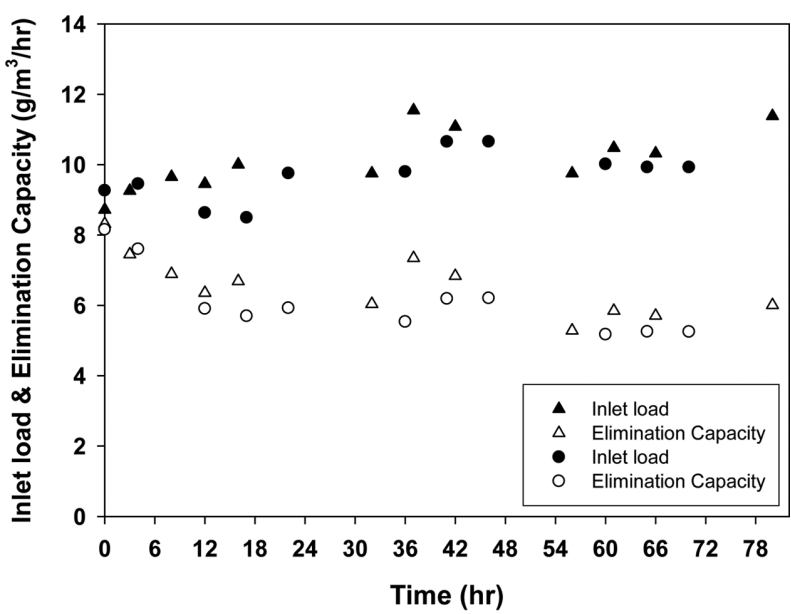

Fig. 13. Time-evolution of inlet load and elimination capacity of toluene of UV/photo-catalytic reactor packed with nonporous glass bead and covered with reflector (triangle) or without any reflector (round).

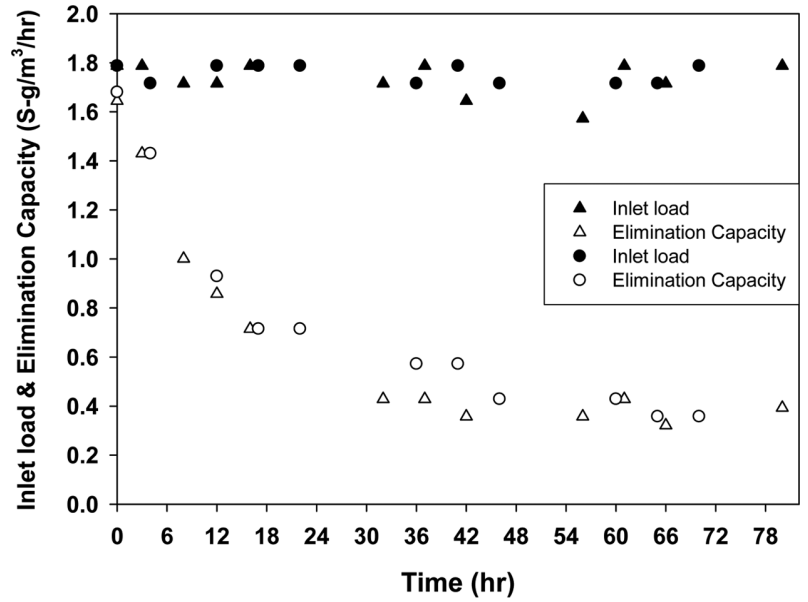

Fig. 14. Time-evolution of inlet load and elimination capacity of hydrogen sulfide of UV/photo-catalytic reactor packed with nonporous glass bead and covered with reflector (triangle) or without any reflector (round).

우의 톨루엔 및 황화수소 제거효율인 각각 $82 \%$ 및 $22 \%$ 와 비교 시 톨루엔 및 황화수소 각각 약 $3 \%$ 및 $2 \%$ 정도 제거율이 높았다. 한편 glass-bead 담체가 충전되고 반사필름이 부착된 개선된 광촉매반응 기의 경우에 톨루엔 및 황화수소 제거효율은 각각 $53 \%$ 및 $20 \%$ 로 서, 반사필름이 부착되지 않은 광촉매반응기 경우의 톨루엔 및 황 화수소 제거효율인 각각 $53 \%$ 및 $20 \%$ 와 비교 시 차이가 미미하였 다. 따라서 glass-bead 담체를 충전했을 때에 개선된 광촉매반응기 의 제거효율 제고효과는 미미하였으나, porous silica-based 담체를 충전했을 때에는 개선된 광촉매반응기의 제거효율 제고효과는 $2 \sim 3 \%$ 이었다.

3-2-4. 최적화 광촉매반응기의 광촉매 처리효율에 대한 영향평가 흡착능과 광도가 동시에 제고되어서 최적화된 광촉매반응기(i.e., porous silica-based 담체로 충전된 개선된 광촉매반응기)와 nonporous glass bead가 충전되고 반사막이 없는 광촉매반응기(control)의 악취

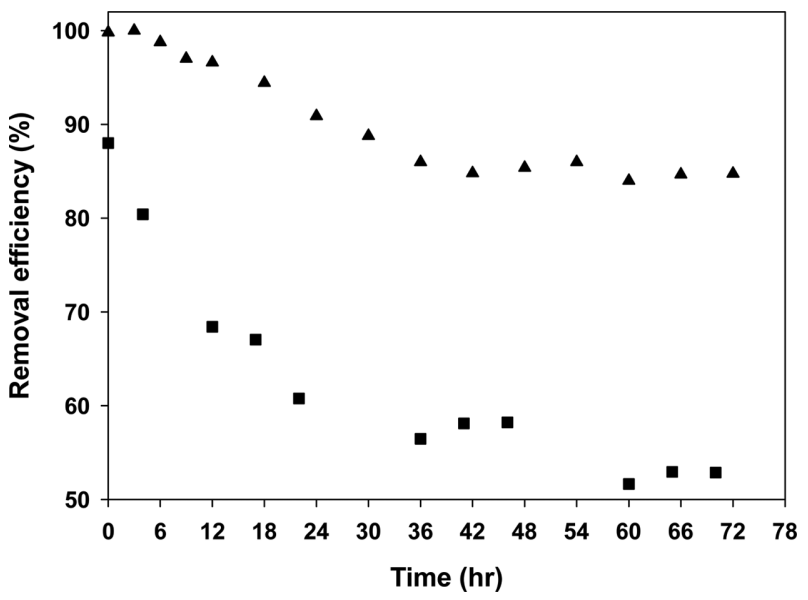

Fig. 15. Removal efficiency of toluene at the exit of UV/photo-catalytic reactor (optimized) packed with silica based porous media and covered with reflector (triangle) or UV/photo-catalytic reactor (control) packed with glass bead media and covered without any reflector (square).

Korean Chem. Eng. Res., Vol. 50, No. 6, December, 2012 


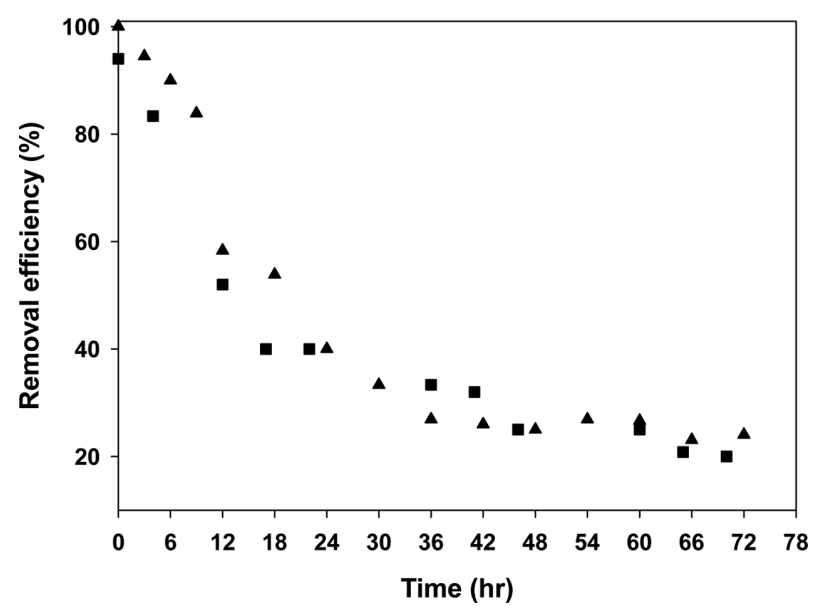

Fig. 16. Removal efficiency of hydrogen sulfide at the exit of UV/ photo-catalytic reactor (optimized) packed with silica based porous media and covered with reflector (triangle) or $\mathrm{UV} /$ photo-catalytic reactor (control) packed with glass bead media and covered without any reflector (square).

와 $\mathrm{VOC}$ 를 함유한 폐가스에 대한 광촉매 처리효율에 대한 비교를 하였다. Porous silica-based 담체가 충전되고 반사필름이 부착되어 최적화된 개선된 광촉매반응기의 경우에 톨루엔 제거효율은 약 $85 \%$ 로서, nonporous glass bead가 충전되고 반사막이 없는 광촉매 반응기의 경우의 $53 \%$ 보다 약 $60 \%$ 의 증가율을 보였다. 한편 최적 화된 개선된 광촉매반응기의 경우에 황화수소 제거효율은 약 $24 \%$ 로서, nonporous glass bead가 충전되고 반사막이 없는 광촉매반응 기의 경우의 $19 \%$ 보다 약 $26 \%$ 의 증가율을 보였다. 최적화 광촉매 반응기와 nonporous glass bead가 충전되고 반사막이 없는 광촉매 반응기 각각의 악취와 $\mathrm{VOC}$ 를 함유한 폐가스에 대한 광촉매 처리 효율 평가는 Figs. 15,16과 같다.

\section{4. 결 론}

광촉매 코팅된 nonporous glass bead 담체와 porous silica-based 담체를 각각 광촉매반응기에 충전하였을 때에 반사필름이 부착된 개선된 광촉매반응기 외경에서 측정한 광도는, 반사필름이 부착되 지 않아서 광도가 제고되지 않은 광촉매반응기보다 광도가 각각 $30.1 \%$ 와 $28.5 \%$ 증가하였다. Porous silica-based 담체가 충전되고 반사필름이 부착된 최적화 개선된 광촉매반응기의 경우에 톨루엔 및 황화수소 제거효율은 각각 $85 \%$ 및 $24 \%$ 로서, 반사필름이 부착 되지 않은 광촉매반응기 경우의 톨루엔 및 황화수소 제거효율인 각 각 $82 \%$ 및 $22 \%$ 와 비교 시 톨루엔 및 황화수소 각각 약 $3 \%$ 및 $2 \%$ 정도 제거율이 높았다. 한편 glass-bead 담체가 충전되고 반사필름 이 부착된 개선된 광촉매반응기의 경우에 톨루엔 및 황화수소 제거 효율은 반사필름이 부착되지 않은 광촉매반응기 경우와 비교 시 차 이가 미미하였다. 또한 최적화 광촉매반응기의 경우의 톨루엔 및 황 화수소 제거효율은 nonporous glass bead가 충전되고 반사막이 없 는 광촉매반응기 경우의 톨루엔 및 황화수소의 제거효율인 각각 $53 \%$ 와 $19 \%$ 보다 각각 약 $60 \%$ 와 약 $26 \%$ 의 증가율을 보였다. 반사 필름 표면과 종래의 상업용 거울의 roughness는 각각 $2.3 \mathrm{~nm}$ 및 $0.5 \mathrm{~nm}$ 로서, 반사막 필름표면의 roughness 가 종래의 상업용 거울의 roughness보다 약간 컸으나, 향후 증착과 같은 방법을 사용하여 개 선된 광촉매반응기의 반사막의 roughness를 개선할 경우에 광도 개 선효과가 더욱 커져서 이에 따른 악취 및 $\mathrm{VOC}$ 를 함유한 광촉매 처 리효율이 더욱 제고되리라 예상된다.

\section{감 사}

본 연구는 교육과학기술부와 한국연구재단의 지역혁신인력양성 사업으로 수행된 연구결과입니다.

\section{참고문헌}

1. Tada, H., Akazawa, M., Kubo, Y. and Ito, S., "Enhancing Effect of $\mathrm{SiOx}$ Monolayer Coverage of $\mathrm{TiO}_{2}$ on the Photoinduced Oxidation of Rhodamine 6G in Aqueous Media,' J. Phys. Chem. B, 102, 6360-6366(1998).

2. Tada, H., Kubo, Y., Akazawa, M. and Ito, S., "Promoting Effect of SiOx Monolayer Coverage of $\mathrm{TiO}_{2}$ on the Photoinduced Oxidation of Cationic Surfactants,' Langmuir, 14, 2936-2939(1998).

3. Jung, K. Y. and Park, S. B., "Effect of Calcination Temperature and Addition of Silica, Zirconia, Alumina on the Photocatalytic Activity of Titania,' Korean J. Chem. Eng., 18, 879-888(2001).

4. Vohra, M. S. and Tanaka, K., "Photocatalytic Degradation of Aqueous Pollutants Using Silica-modified $\mathrm{TiO}_{2}$, Water Res., 37, 3992-3996(2003).

5. Nakano, K., Obuchi, E., Takagi, S., Yamamoto, R., Tanizaki, T., Taketomi, M., Ichida, K., Suzuki, M. and Hashimoto, A., "Photocatalytic Treatment of Water Containing Dinitrophenol and City Water over $\mathrm{TiO}_{2} / \mathrm{SiO}_{2}$," Sep. Purif. Technol., 34, 67-72(2004).

6. Ismail, A. A., Ibrahim, I. A., Ahmed, M. S., Mohamed, M. R. and El-Shall H., "Sol-gel Synthesis of Titania-silica Photocatalyst for Cyanide Photodegradation,', J. Photochem. Photobiol. A-Chem., 163, 445-451(2004).

7. Zou, L., Luo, Y., Hopper, M. and Hu, E., "Removal of VOCs by Photocatalysis Process Using Adsorption Enhanced $\mathrm{TiO}_{2}-\mathrm{SiO}_{2}$ Catalyst,' Chem. Eng. Process., 45, 959-964 (2006).

8. Wang, Y. M., Liu, S. W., Xiu, Z., Jiao, X. B., Cui, X. P. and Pan, J., "Preparation and Photocatalytic Properties of Silica Gel-supPorted $\mathrm{TiO}_{2}$," Material Letters, 60, 974-978(2006).

9. Tanaka, K., Fukuyoshi, J., Segawa, H. and Yoshida, K., "Improved Photocatalytic Activity of Zeolite- and Silica-incorporated $\mathrm{TiO}_{2}$ Film,' J. Hazard. Mater, B137, 947-951(2006).

10. Marugan, J., Hufschmidt, D., Lopez-Munez, M., Seltzer, V. and Bahnemann, D., "Photonic Efficiency for Methanol Photooxidation and Hydroxyl Radical Generation on Silica-supported $\mathrm{Tio}_{2}$ Photocatalysts,' Appl. Catal. B: Environ., 62, 201-207(2006).

11. Subramanian, M. and Kannan, A., "Photocatalytic Degradation of Phenol in a Rotating Annular Reactor,' Chem. Eng. Sci., 65, 2727-2740(2010).

12. Okamoto, K., Yamamoto, Y. and Tanaka, H., "Kinetics of Heterogeneous Photocatalytic Decomposition of Phenol over Anatase $\mathrm{TiO}_{2}$ Power,' Bull Chem. Soc. Jpn., 58, 2023-2027(1985).

13. D'oliveira, J. C., Ghassan, A. S. and Pichat, P., "Photodegradation of 2- and 3-chlorophenol in $\mathrm{TiO}_{2}$ Aqueous Suspensions,' Environ Sci. Technol., 24, 990-996(1990).

14. Ollis, D. F., Pelizzetti, E. and Serpone, N., "Photocatalyzed Destruc-

Korean Chem. Eng. Res., Vol. 50, No. 6, December, 2012 
tion of Water Contaminants"', Environ Sci. Technol., 25, 1522-1528 (1991).

15. Yang, L. and Liu, Z., "Study on Light Intensity in the Process of Photocatalytic Degradation of Indoor Gaseous Formaldehyde for Saving Energy,' Energy Conv. Manag., 48, 882-889(2007).

16. Lim, K. H., Park, S. W., Lee, E. J. and Hong, S. H., "Treatment of Mixed Solvent Vapors with Hybrid System Composed of Biofilter and Photo-catalytic Reactor,' Korean J. Chem. Eng., 22(1), 70-79(2005).

17. Lee, E. J. and Lim, K. H., "Treatment of Malodorous Waste Air Using Hybrid System,', Korean Chem. Eng. Res.(HWAHAK KONG$H A K)$, 48(3), 382-390(2010). 